\title{
Conversion to Gastric Bypass in Patients with Unsuccessful Weight Loss after Gastric Banding May Depend on Mental Quality of Life
}

\author{
Junilla K. Larsen ${ }^{\mathrm{a}}$ Hanna Zijlstra ${ }^{\mathrm{b}}$ Bert van Ramshort ${ }^{\mathrm{c}} \quad$ Rinie Geenen $^{\mathrm{d}}$ \\ ${ }^{a}$ Behavioural Science Institute, Radboud University Nijmegen, P.O. Box 9104, 6500 HE Nijmegen, \\ ${ }^{\mathrm{b}}$ School of Sports and Nutrition, University of Applied Sciences, Amsterdam, \\ ${ }^{\mathrm{c}}$ Department of Surgery, St. Antonius Hospital, Nieuwegein, \\ ${ }^{d}$ Department of Clinical and Health Psychology, Utrecht University, and Department of Rheumatology and Clinical Immunology, \\ University Medical Center Utrecht, Utrecht, the Netherlands
}

\section{Key Words}

Morbid obesity - Bariatric surgery - Mental health . Quality of life · Conversion

\section{Summary}

Background: A low quality of life has been regarded a cue to action. Some patients with unsuccessful weight loss after laparoscopic adjustable gastric banding (LAGB) undergo a conversion of gastric banding to gastric bypass. This study examines whether patients who did or did not undergo conversion to gastric bypass differed in quality of life before and after gastric banding. Methods: Of 34 patients with unsuccessful weight loss after gastric banding (excess body mass index loss $<25 \%$ ), 14 had a conversion to gastric bypass 2 years or more after gastric banding. All patients completed the RAND-36 quality of life questionnaire before gastric banding. After gastric banding, 24 patients $(70.6 \%)$ filled out the RAND-36 at 6,12 , and 24 months. Results: Pre-banding and postbanding mental quality of life was lower in the conversion compared to the non-conversion group. Conclusion: Our results suggest that a relatively stable lower mental quality of life is a signal for further intervention. The bariatric team and patients should be aware that mental health may play a role in the decision for conversion to gastric bypass. The possible mechanisms underlying this finding, and limitations of the study are discussed.

\section{Introduction}

Laparoscopic adjustable gastric banding (LAGB) is a widely used restrictive bariatric operation [1]. Due to its reversibility and adjustability, it is considered to be the least invasive bariatric procedure [2]. However, the weight loss resulting from gastric banding is less compared to a combined restrictive and malabsorptive procedure like gastric bypass [3]. Some patients with insufficient weight loss after gastric banding undergo conversion to gastric bypass, which often results in superior weight loss [4-6].

Clarification of the factors that affect the decision of patients and surgeons to convert to gastric bypass when gastric banding has led to unsuccessful weight loss will help the discussion about the appropriateness of these factors. To date, no studies have addressed this question. Health psychology theories emphasize that perceived consequences of obesity determine health behaviors [7, 8]. A low quality of life is considered a 'cue to action', i.e. a signal that a change of health status is needed. In line with this idea, lower levels of quality of life have been associated with treatment-seeking behavior in obesity [9]. Severely obese persons seeking surgical obesity treatment demonstrated on average the worst quality of life compared to other overweight and obese populations; even after adjustment for weight [10].

The aim of the present study was to examine whether patients who did or did not undergo conversion to gastric bypass differed in pre-conversion quality of life. Quality of life was assessed before gastric banding and several times after gastric banding, but before conversion. We hypothesized that 'unsuccessful' patients who have a conversion operation are the ones with a lower pre-conversion quality of life.

\section{KARGER}

Fax +497614520714

Information@Karger.de

www.karger.com (c) 2010 S. Karger GmbH, Freiburg 
Table 1. Pre-surgical demographic characteristics of the conversion and non-conversion groups $^{\mathrm{a}}$

\begin{tabular}{llll}
\hline & Conversion & Non-conversion & Test variable \\
\hline Number of patients & 14 & 20 & \\
Ratio females:males & $13: 1$ & $16: 4$ & $\chi^{2}=1.09$ \\
Mean age, years (SD) & $39.4(10.2)$ & $41.9(8.3)$ & $\mathrm{t}=0.77$ \\
Marital status, $(\%$ married) & 78.6 & 70.0 & $\chi^{2}=0.31$ \\
Mean BMI, kg $/ \mathrm{m}^{2}$ (SD) & $49.5(6.2)$ & $49.4(7.3)$ & $\mathrm{t}=-0.06$ \\
Education level, $\mathrm{n}$ & & & $\chi^{2}=0.99$ \\
$\quad$ Primary & 2 & 1 & \\
$\quad$ Secondary & 11 & 18 & \\
$\quad$ Tertiary & 1 & 1 & \\
\hline
\end{tabular}

${ }^{a}$ None of the group differences were significant.

\section{Material and Methods}

\section{Patients and Procedures}

Between November 2000 and April 2004, 156 patients were subjected to a LAGB procedure at the St. Antonius Hospital Nieuwegein, the Netherlands, using the Lap-Band ${ }^{\circledR}$ system (INAMED Health, Santa Barbara, CA, USA), following screening by a bariatric surgeon, an endocrinologist, a psychologist, and a dietician. Surgical indications were a BMI $\geq 40$ or a BMI between 35 and 40 with serious co-morbidity. The operation was performed according to the techniques described by Belachew et al. [11]. Weight observations after surgery were recorded in the hospital. Weight outcome was defined as percent of excess body mass index loss (\%EBL) according to standard procedures [12]. We selected patients with unsuccessful weight outcome 2 years or more after LAGB (defined as $\% \mathrm{EBL}<25 \%$ ) out of a group of 113 patients who participated in a survey study which has received the necessary ethical approval [13]. We used the last weight observation after LAGB and if applicable before conversion to gastric bypass that was recorded. Thirty-four of the 113 patients $(30 \%)$ had an unsuccessful weight outcome $(\% \mathrm{EBL}<25 \%)$. Of these 'unsuccessful' patients, 14 underwent conversion to gastric bypass. There were no differences in the \%EBL between the conversion group $($ mean $(\mathrm{M})=11.7$; standard deviation $(\mathrm{SD})=10.9)$ and non-conversion group $(\mathrm{M}=12.5 ; \mathrm{SD}=13.5), \mathrm{t}(32)=0.2, \mathrm{p}=0.85$. Because for the conversion group, the post-banding weight evaluation ended when the bypass operation was performed, the post-operative follow-up interval recorded in months of the last weight observation was longer for the non-conversion group $(\mathrm{M}=57.9 ; \mathrm{SD}=17.4)$ compared to the conversion group $(\mathrm{M}=45.0 ; \mathrm{SD}=14.8), \mathrm{t}(32)=2.2, \mathrm{p}=0.03$. The conversion operation was conducted on average 48 months $(\mathrm{SD}=15.6$; range $=23.7-77.9)$ after gastric banding. The groups did not differ in demographic characteristics, as shown in table 1 . All patients completed the quality of life measure before gastric banding. After gastric banding, 24 patients (70.6\%) filled out the quality of life measure at 6,12 , and 24 months post-banding, and 10 of these 24 patients were in the conversion group. There were no differences between the patients who did or did not complete all post-operative quality of life measures on demographic characteristics, BMI, or pre-banding quality of life $(p>0.10)$. For the 24 patients who filled out all post-operative quality of life measures, the conversion operation was conducted on average 53.9 months $(\mathrm{SD}=14.6$; range $=40.2-77.9)$ after gastric banding and 28.5 months $(\mathrm{SD}=14.5$; range $=13.0-51.2)$ after patients filled out the last quality of life measure. Repeated measures analyses of variance examining \%EBL at 6,12, and 24 months post-banding showed no group differences in the level $(\mathrm{F}=0.81, \mathrm{p}=0.38)$ or change $(\mathrm{F}=1.15, \mathrm{p}=0.29)$ of \%EBL across the repeated measurements for the 24 patients who filled out all post-operative quality of life measures. Mean \%EBL across measurements was 31.3 (confidence interval $(\mathrm{CI})=23.6-39.0$ ) for the non-conversion group and $26.1(\mathrm{CI}=16.9-35.2)$ for the conversion group.
For some patients the \%EBL from 6 to 24 months after gastric banding was higher than $25 \%$, but all patients fulfilled the $25 \%$ criterion during the last weight observation recorded.

\section{Quality of Life Measurements}

To measure quality of life, the RAND-36 was used [14]. Quality of life scores of the separate subscales were expressed as mean deviations from a general Dutch norm population [14]. The lower scores reflect poorer health as compared to age and gender-specific norms. We also used the scores of the 8 subscales of the RAND-36 to calculate 2 summary scores by a standard equation: Physical Component Summary (PCS or physical health) and Mental Component Summary (MCS or mental health) [15].

\section{Statistical Analysis}

Though the sample sizes were rather small, the score distributions of all quality of life dimensions were sufficiently normal to allow parametric statistics [16]. The quality of life before gastric banding of the conversion and non-conversion groups were examined with independent sample ttests for all 34 patients. In 24 patients, repeated measures analyses of variance were used on pre-banding and 6,12 and 24 post-banding quality of life with group (conversion versus non-conversion) as between-subject factor. For the subscale 'emotional role limitations', the analyses were run on 23 patients, as from 1 patient information was missing. Effects sizes (Cohen's d) were computed. Effect sizes between 0.2 and 0.5 reflect a small effect, between 0.5 and 0.8 a medium effect, and above 0.8 a large effect [17]. Analyses were performed with SPSS 15.0 (SPSS Inc., Chicago, IL, USA); $p$ values of less than 0.05 were considered to be significant.

\section{Results}

Table 2 shows the pre-banding quality of life for the conversion and non-conversion groups. Patients with and without conversion did not differ significantly on pre-banding social and physical quality of life, but the conversion group showed a worse pre-banding mental quality of life, as reflected in significantly lower scores on the subscales 'emotional role limitations' $(p<0.05)$ and 'mental health' $(p<0.05)$, and a just not significant lower score on the MCS score $(p=0.05)$. The prebanding differences between groups that were significant were moderate to large with effect sizes varying between 0.71 and 0.77 (Cohen's d). Also repeated measures analyses of variance that examined quality of life across all measurements showed lower levels on the subscales 'emotional role limita- 
Table 2. Mean (standard deviation) presurgical quality of life of the conversion and non-conversion groups

\begin{tabular}{lrrrrrrr}
\hline & \multicolumn{2}{l}{ Conversion $(\mathrm{n}=14)$} & & \multicolumn{2}{c}{ Non-conversion $(\mathrm{n}=20)$} & \multirow{2}{*}{$\mathrm{t}$} \\
\cline { 2 - 3 } & $\mathrm{M}$ & $\mathrm{SD}$ & & $\mathrm{M}$ & $\mathrm{SD}$ & \\
\hline Physical functioning & -51.6 & 25.5 & & -39.8 & 27.5 & 1.26 \\
Social functioning & -39.4 & 4.0 & & -37.5 & 15.9 & 0.50 \\
Physical role limitations & -43.2 & 41.9 & & -26.0 & 41.1 & 1.17 \\
Emotional role limitations & -38.2 & 48.6 & & -3.8 & 41.0 & $2.19^{\mathrm{a}}$ \\
Mental health & -21.9 & 14.1 & & -13.9 & 7.5 & $2.15^{\mathrm{a}}$ \\
Vitality & -20.8 & 10.8 & & -16.7 & 9.4 & 1.18 \\
Pain & -24.9 & 28.8 & & -43.9 & 34.1 & -1.69 \\
General health & -17.7 & 10.7 & & -17.6 & 10.7 & 0.04 \\
MCS score & 38.3 & 15.5 & & 48.5 & 12.9 & $2.00^{\mathrm{b}}$ \\
PCS score & 34.0 & 10.5 & & 35.3 & 11.7 & 0.32 \\
\hline
\end{tabular}

${ }^{\mathrm{a}} \mathrm{p}<0.05$.

${ }^{\mathrm{b}} \mathrm{p}=0.05$.
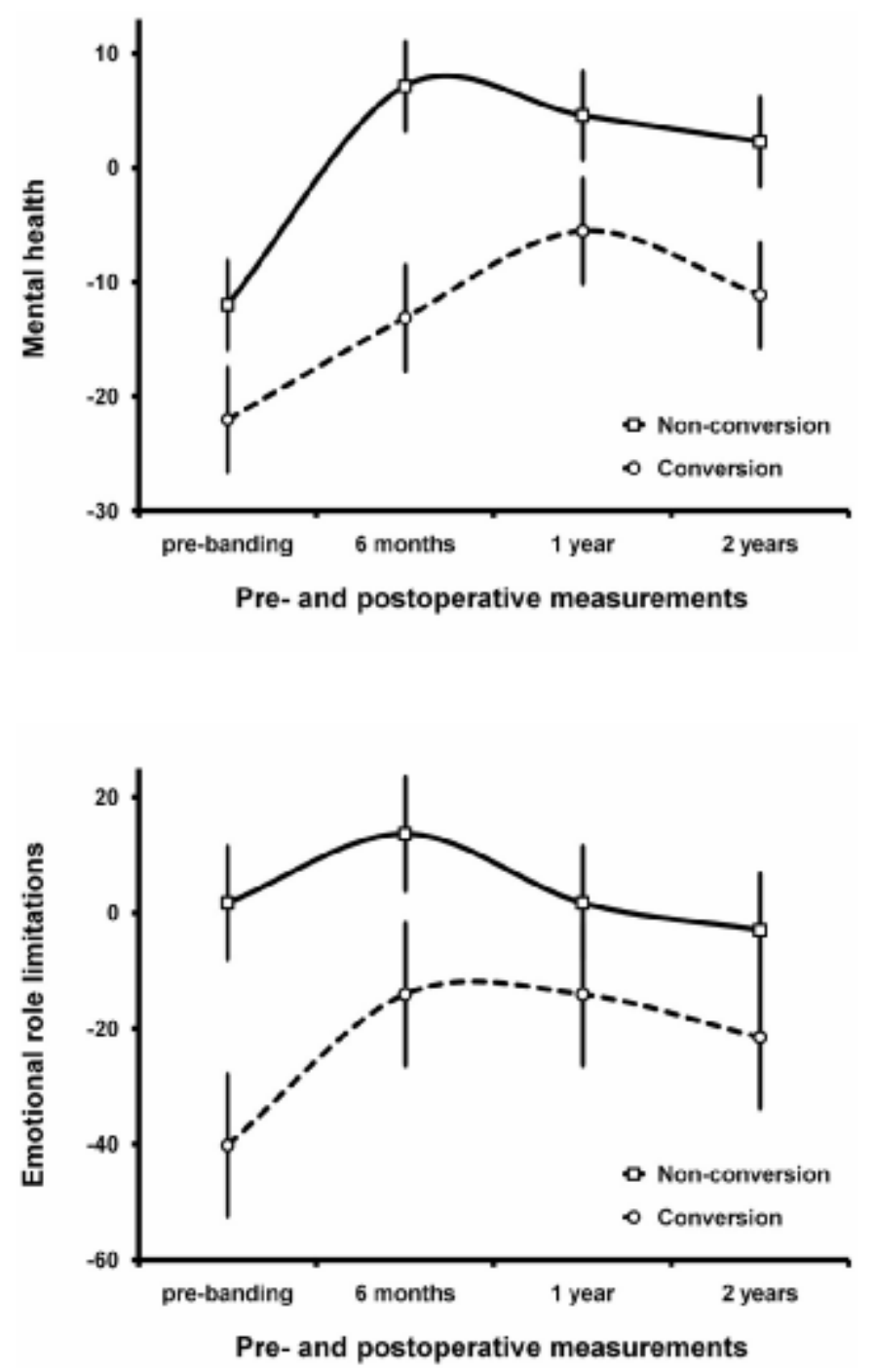

Fig. 1. Pre-banding and post-banding scores on 'mental health' and 'emotional role limitations' for the conversion and non-conversion group. tions' $(\mathrm{F}=5.45, \mathrm{p}=0.03)$, 'mental health' $(\mathrm{F}=9.15, \mathrm{p}=0.006)$, and on the MCS score $(\mathrm{F}=8.86, \mathrm{p}=0.008)$ for the conversion group. These effects were all large in terms of effect sizes (Cohen's $d>1$ ). Figure 1 shows the scores for 'emotional role limitations' and 'mental health'. There were no differences in the change of quality of life across the 4 repeated measurements between the conversion and non-conversion group ( $p>0.10$ for all quality of life measures). Ancillary analyses showed that pre-banding patients with conversion also reported more lifetime psychological treatment $(64.3 \%)$ compared to the non-conversion group $(30.0 \%), \chi^{2}=3.9, p=0.048$. We repeated these analyses for females only, and the same effects were found.

\section{Discussion}

This is the first study to examine a psychological characteristic of patients who did or did not undergo conversion to gastric bypass for unsuccessful weight loss following gastric banding. The mental quality of life of patients who had a conversion to gastric bypass proved to be enduringly worse compared to those who did not have a conversion. Our results suggest that a low mental quality of life is a signal for further intervention.

We expected that a worse quality of life could be a 'cue to action' $[7,8]$, in this case conversion to gastric bypass. Notably, we found a significant effect for mental quality of life, but not physical or social functioning. This may suggest that especially psychologically distressed patients are more likely to seek additional surgical treatment or to accept conversion to gastric bypass when it is offered. Another hypothesis is that patients with relatively good mental strength do not choose gastric bypass, because they believe that they are still capable to restrict food intake with the help of the gastric band. Besides the decisions of the patient, also decisions of the surgeon may play a role. Perhaps the decision to offer gastric bypass as 
an additional intervention is postponed for patients who are considered to have relatively high mental strength.

Our study has some limitations. First, we have no insight into the hypothesized mechanisms underlying the finding that 'unsuccessful' patients with a relatively stable low mental health undergo conversion. Second, the sample size is small, although it was large enough to detect a moderate to large group difference in mental quality of life. Third, although our results convincingly indicate relative stability in mental health among our groups, we have no information on mental quality of life just before conversion. It would be useful to eventually develop a pre-operative algorithm to prevent conversions and let some patients have a gastric bypass from the beginning. Our study suggests that quality of life could be part of such an algorithm. Future studies should repeat our study results in larger samples and examine the hypothesized mechanisms underlying our finding. Overall, the bariatric team and patients should be aware that patient's mental health may play a role in the decision for conversion to gastric bypass.

\section{Disclosure}

The authors declared no conflicts of interest.

\section{References}

1 Salameh JR: Bariatric surgery: past and present. Am J Med Sci 2006;331:194-200.

$\checkmark 2$ Saber AA, Elgamal MH, McLeod MK: Bariatric surgery: the past, present, and future. Obes Surg 2008;18:121-128.

-3 Chapman AE, Kiroff G, Game P, Foster B, O'Brien P, Ham J, Maddern GJ: Laparoscopic adjustable gastric banding in the treatment of obesity: a systematic literature review. Surgery 2004;135: 326-351.

4 Gagner M, Gumbs AA: Gastric banding: conversion to sleeve, bypass, or DS. Surg Endosc 2007;21: 1931-1935.

5 Kothari SN, DeMaria EJ, Sugerman HJ, Kellum JM, Meador J, Wolfe L: Lap-band failures: conversion to gastric bypass and their preliminary outcomes. Surgery 2002;131:625-629.

6 Mognol P, Chosidow D, Marmuse JP: Laparoscopic conversion of laparoscopic gastric banding to roux-en-y gastric bypass: a review of 70 patients. Obes Surg 2004;14:1349-1353.
Leventhal H, Leventhal EA, Contrada RJ: Selfregulation, health, and behavior: a perceptual-cognitive approach. Psychol Health 1998;13:717-733.

8 Rosenstock IM, Strecher VJ, Becker MH: Social learning theory and the health belief model. Health Educ Q 1988;15:175-183.

$\checkmark$ Fontaine KR, Bartlett SJ, Barofsky I: Health-related quality of life among obese persons seeking and not currently seeking treatment. Int J Eat Disord 2000;27:101-105.

10 van Nunen AM, Wouters EJ, Vingerhoets AJ, Hox JJ, Geenen R: The health-related quality of life of obese persons seeking or not seeking surgical or non-surgical treatment: a meta analysis. Obes Surg 2007;17:1357-1366.

11 Belachew M, Legrand MJ, Defechereux TH, Burtheret MP, Jacquet N: Laparoscopic adjustable silicone gastric banding in the treatment of morbid obesity. A preliminary report. Surg Endosc 1994;8: 1354-1356.

12 Deitel M, Gawdat K, Melissas J: Reporting weight loss 2007. Obes Surg 2007;17:565-568.
3 Zijlstra H, Larsen JK, de Ridder DT, van Ramshorst B, Geenen R: Initiation and maintenance of weight loss after laparoscopic adjustable gastric banding. The role of outcome expectation and satisfaction with the psychosocial outcome. Obes Surg 2009;19:725-731.

14 Van der Zee KI, Sanderman R, Heyink JW, De Haes JC: Psychometric qualities of the rand 36item health survey 1.0: a multidimensional measure of general health status. Int J Beh Med 1996;3:104 122.

15 Ware JE, Kosinski M, Keller SD: Physical and Mental Health Summary Scales - A User's Manual. Boston, MA, New England Medical Center, The Health Institute, 1994.

16 Tabachnick BG, Fidell LS: Using Multivariate Statistics, 4th ed. Boston, MA, Allyn and Bacon, 2001.

17 Cohen J: Statistical Power Analysis for the Behavioral Sciences, 2nd ed. Hillsdale, NJ, Lawrence Erlbaum Associates, 1988. 